\title{
Konsep Penyesuaian Sosial Anak Berbakat
}

\author{
Sofia Pilosusan ${ }^{1}$, Monika Veronika², Egin Elga Dean Sum ${ }^{3}$ \\ ${ }^{123}$ Universitas Negeri Padang \\ *) Correspondence regarding this article should be addressed to: Author address e-mail: \\ sopiapilosusan@gmail.com
}

\begin{abstract}
Individu yang terlahir di dunia tentunya memiliki bakat, akan tetapi bakat tersebut belum bisa diketahui secara spesifik dikarenakan masih berada pada tahap perkembangan awal. Seiring berjalannya waktu, individu dapat mengetahui bakat yang dimilikinya dan apabila ia mampu mengembangkan bakatnya maka ia memiliki suatu hal yang menjadi kebanggaan dirinya. Banyak ditemukan hambatan pada anak berbakat, salah satunya dalam penyesuaian sosial. Anak berbakat yang terlalu memfokuskan diri pada pengembangan bakatnya akan menjadi individu yang tidak mampu bersosialisasi dengan baik.
\end{abstract}

Keywords: Anak Berbakat, Penyesuaian Sosial

Article History: Received on 04/03/2019; Revised on 10/04/2019; Accepted on 21/04/2019; Published Online: 30/04/2019.

This is an open access article distributed under the Creative Commons Attribution License, which permits unrestricted use,
distribution, and reproduction in any medium, provided the original work is properly cited. (C)2019 by author.

PENDAHULUAN

Menurut (Salisah, Lidya, \& Defit, 2015)bakat adalah kemampuan alamiah untuk memperoleh pengetahuan atau keterampilan yang bisa bersifat umum atau khusus.Anak berbakat sering mengalami dilema excellence versusintimacy (Gross, 1989). Bila anak memilih untuk berfokus padakeunggulan maka ia mengambil risiko hilangnya kedekatan dengan teman sebaya, namun bila ia memilih konformitas terhadap kelompok maka ia akan terdesak pada underachievement demi mempertahankan keanggotaan dalam kelompok (Gross, 1989).

Konsep Keberbakatan

Menurut (Salisah, Lidya, \& Defit, 2015)bakat adalah kemampuan alamiah untuk memperoleh pengetahuan atau keterampilan yang bisa bersifat umum atau khusus. Ada enam bakat menurut US Office OfEducation (USOE) America (Salisah, Lidya, \& Defit, 2015), yaitu: (1)intelektual umum; (2) akademik khusus; (3) berfikir kreatif-produktif; (4) kemampuan memimpin; (5) bidang seni dan pertunjukkan; (6) kemampuan psikomotor.

“Gallardo-Gallardo, Dries, and Gonzales-Cruz (2013) present a broad, in-depth analysis of the term of talent stating that talent may be conceptualized as naturalability, 
mastery, commitment and fit revealed in innate abilities, acquired skills, knowledge, skills and attitudes".

“Gallardo-Gallardo, Dries, and Gonzales-Cruz (2013)menyajikan analisis mendalam tentang istilah bakat yang menyatakan bahwa bakat dapat dikonseptualisasikan sebagai kemampuan alamiah, penguasaan, komitmen, dan kecocokan yang terungkap dalam kemampuan bawaan, keterampilan yang diperoleh, pengetahuan, keterampilan, dan sikap."

Utami Munandar (Fernanda \& Sano, 2012) menyatakan bahwa siswa unggul atau siswa berbakat adalah mereka yang mampu mencapai prestasi tinggi dan mempunyai kemampuan-kemampuan yang unggul. Menurut (Jaenudin, 2010) anak-anak tersebut memerlukan program pendidikan yang berdiferensiasi dan atau pelayanan di luar jangkauan program sekolah biasa agar dapat merealisasikan sumbangan mereka terhadap masyarakat maupun untuk pengembangan diri sendiri. Menurut Seligman \& Csikszentmihalyi (Churni \& Ifdil, 2017) keberbakatan merupakan interaksi antara kemampuan umum dan atau spesifik, tingkat tanggung jawab terhadap tugas yang tinggi, dan tingkat kreativitas yang tinggi.

Pada dasarnya keberbakatan anak adalah bukan suatu hal yang bersifat statis, tapi ia bersifat dinamis(Tahrir, 2009). Keberbakatan seorang anak dapat ditelusuri, digali, dan dikembangkan, sehingga dapat dijadikan modal dasar dalam menghadapi suatu kehidupan yang penuh tantangan, hambatan, dan rintangan(Tahrir, 2009).

Karakteristik Anak Berbakat

Hasil-hasil penelitian, pengamatan, ataupun pengalaman menunjukkan bahwa anak berbakat memiliki karakteristik dan kebutuhan yang berbeda dari anak lain pada umumnya(Rahman, 2015). Karakteristik dan kebutuhan itu mencakup aspek-aspek: intelektual, akademik, kreativitas, kepemimpinan dan sosial, seni, afeksi, sensori fisik, intuisi, dan ekologis (Rahman, 2015).

Menurut (Wandansari \& Y, 2012) seiring berkembangnya konsep kecerdasan, konsep teoritis keberbakatan juga mengalami perubahan dari pendekatan unidimensional menuju multidimensional. Mengacu pada teori three-conceptions of giftedness yang dikemukakanoleh Renzulli (Wandansari \& Y, 2012), karakteristik keberbakatan mencakup 3 hal, yaitu kemampuan di atas rata-rata, komitmen pada tugas, dan kreativitas. Renzulli (Wandansari \& Y, 2012) menegaskan bahwa diantara tiga karakteristik tersebut, tidak ada karakteristik tunggal yang menciptakan keberbakatan, melainkan interaksi ketiganya sangat penting untuk mencapai prestasi kreatif-produktif dan memunculkan perilaku keberbakatan.

Kitano and Kirby (Wahab \& R, 2010) menegaskan bahwa karak-teristik ABA di antaranya: (1) memiliki rentangan perhatian yang lama dikaitkan dengan bidang akademik tertentu;(2)memiliki pemahaman konsep, metode, dan terminologi pada tingkat lanjut untuk bidang tertentu; (3) mampu me-nerapkan konsep-konsep dari bidang tertentu ke kegiatan-kegiatan dalam bidang lainnya; (4) adanya keinginan untuk mencurahkan sebagian besar waktu dan usahanya untuk mencapai standar yang tinggi dalam suatu bidang akademik tertentu; (5) adanya kemampuan kompetitif dalam bidang akademik tertentu dan motivasi untuk berbuat yang terbaik; (6) kemampuan belajar cepat 
dalam bidang studi tertentu; dan (7) memiliki keajegan dan dikendalikan oleh tujuan dalam bidang tertentu.

Beberapa karakteristik anak berbakat intelektual, yang umum menurut Tuttler, Becker, dan Sausa dalam Reni Akbar, (Ilyas, 2012)adalah:

1. Ingin Tahu

2. Tekun dalam mengejar minat dan pertanyaan-pertanyaan

3. Cepat memahami lingkungan

4. Kritis pada diri sendiri dan orang lain

5. Rasa humor tinggi

6. Peka terhadap ketidakadilan pada perseorangan maupun tingkat yang lebih luas

7. Pemimpin di banyak area

8. Tidak mau menerima pernyataan, respond an penilaian yang dangkal

9. Memahami dengan mudah prinsip-prinsip umum

10. Seringkali bereaksi dengan lingkungan melalui media dan lainnya daripada dicetak dan ditulis

11. Melihat hubungan-hubungan diantara gagasan-gagasan yang berbeda

12. Mengangkat banyak gagasandri stimulus yang spesifik

Penyesuaian Sosial

Menurut Hurlock (Solikhatun, 2013) penyesuaian sosial diartikan sebagai keberhasilan seseorang untuk menyesuaikan diri terhadap orang lain pada umumnya dan terhadap kelompoknya pada khususnya. Schneider (Wandansari \& Y, 2012) menjelaskan bahwa penyesuaian pada manusia terjadi ketika terdapat tuntutan tertentu yang harus dipenuhi, atau pada saat ada kesulitan, konflik, atau frustrasi yang harus diselesaikan. Menurut Schneider (Wandansari \& Y, 2012) salah satu jenis penyesuaian adalah penyesuaian sosial. Menurut Hurlock (Wandansari \& Y, 2012)sebagai sebuah keberhasilan seseorang dalam menyesuaikan diri dengan orang lain dan dengan kelompoknya, penyesuaian sosial dapat dilihat dari kemampuan untuk membangun relasi yang sehat dengan orang lain sehingga orang lain akan bersikap positif dan menerimanya dengan baik.

Permasalahan Anak Berbakat

Para guru dan konselor yang menangani anak berbakat menemukan adanya hambatan pada anak berbakat dalam relasi sosial, terisolir dari teman sebaya, sulit menerima kritik, non konformis, dan menolak otoritas (Kesner, 2005). Anak berbakat sering mengalami dilema excellence versusintimacy(Gross, 1989). Bila anak memilih untuk berfokus padakeunggulan maka ia mengambil risiko hilangnya kedekatan dengan teman sebaya, namun bila ia memilih konformitas terhadap kelompok maka ia akan terdesak pada underachievement demi mempertahankan keanggotaan dalam kelompok (Gross, 1989). 
Seagoe (Hawadi, 1985) menjelaskan bahwa ciri-ciri tertentu dari anak berbakat dapat atau mungkin mengakibatkan timbulnya masalah-masalah tertentu, seperti:

1. Kemampuan berpikir tingkat tinggi dapat mengarah ke sikap ragu-ragu (skeptis) dan sikap kritis baik terhadap diri maupun lingkungan.

2. Kemampuan kreatif dan minat untuk melakukan hal-hal baru bisa menyebabkan anak berbakat tidak menyukai atau cepat bosan terhadap tugas rutin.

3. Perilaku ulet dan terarah pada tujuan yang sering tampak pada anak berbakat ke arah keinginan untuk memaksakan atau mempertahankan pendapatnya.

4. Kepekaan dari anak berbakat dapat membuatnya mudah tersinggung atau peka terhadap kritik orang lain.

5. Semangat yang tinggi, kesiagaan mental dan prakarsanya dapat membuatnya kurang sabar atau kurang toleran jika tidak ada kegiatan atau kurang tampak kemajuan dalam kegiatan yang sedang berlangsung.

6. Dengan kemampuan dan minatnya yang beragam, anak berbakat membutuhkan keluwesan dan dukungan untuk dapat menjajaki dan mengembangkan minatminatnya.

7. Keinginan anak untuk mandiri dalam belajar dan bekerja, kebutuhan kebebasan dapatmenimbulkan konflik karena tidak mudah menyesuaikan diri atau tunduk terhadap tekanan orang tua atau teman sebaya. Ia dapat juga merasa ditolak atau kurang dimengerti oleh lingkungannya.

\section{KESIMPULAN}

Penyesuaian sosial anak berbakat yang kurang baik bukan lagi menjadi hal baru dalam dunia pendidikan. Oleh karena itu sangat dibutuhkan konselor dalam mengentaskan permasalahan yang dihadapi anak berbakat yang kurang mampu dalam menyesuaikan dirinya dengan lingkungan. Salah satu upaya konselor adalah memberikan bimbingan kelompok agar nantinya anak berbakat bisa melakukan interaksi yang baik dengan anggota kelompok dan nantinya akan membantunya dalam hubungan sosial. Semoga kedepannya, anak berbakat lebih diperhatikan lagi dalam lingkungan pendidikan dan masyarakat agar potensi yang dimiliknya berkembang secara optimal.

\section{REFERENCES}

Churni, E., \& Ifdil, I. (2017). Guidance and Counseling Service for Gifted Children. Proseding.

Fernanda, M. M., \& Sano, A. (2012). Hubungan antara Kemampuan Berinteraksi Sosial dengan Hasil Belajar. Konselor, 1(2).

Gallardo-Gallardo, E., Dries, N., \& González-Cruz, T.F. (2013). What is the meaning of 'talent' in the world of work?, Human Resource Management Review, 23(4): 290300.

Gross, M. (1989). The pursuit of excellence or the search of intimacy? The forced-choice dilemma of gifted youth. Roeper Review, 11 (4), pp, 189-194. 
Hawadi, R. A. (1985). royek Uji Coba Anak Berbakat Sebagai Wahana Pengembangan Potensi Generasi Muda Indonesia. Makalah pada Kogres ISPI di Jakarta tanggal 710 Nopember 1985.

Ilyas, A. (2012). Bahan Ajar Pendidikan Anak Berbakat. Padang: BK FIP UNP.

Jaenudin, U. (2010). Pendidikan Kontruktivistik Dalam Pengembangan Keberbakatan Anak. Psympathic: Jurnal Ilmiah Psikologi, 3(2), 223-231.

Kesner, J. (2005). Gifted children's relationship with teachers. International Education Journal, 6 (2), pp, 218-223.

Rahman, M. M. (2015). Keberbakatan Anak Berkebutuhan Khusus di SD LB Purwosari Kudus. Jurnal Penelitian, 9(2), 275-294.

Salisah, F. N., Lidya, L., \& Defit, S. (2015). Sistem Pakar Penentuan Bakat Anak Dengan Menggunakan Metode Forward Chaining. Jurnal Ilmiah Rekayasa Dan Manajemen Sistem Informasi, 1(1), 62-66.

Solikhatun, Y. U. (2013). Penyesuaian Sosial Pada Penyandang Tunarungu di SLB Negeri Semarang. Educational Psychology Journal, 2(1).

Tahrir, T. (2009). Pola Pengembangan Keberbakatan Dan Pembentukan Kedisiplinan Anak. Psympathic: Jurnal Ilmiah Psikologi, 1(1), 39-50.

Wahab, \& R. (2010). Konseling bagi anak berbakat akademik. Cakrawala Pendidikan, (1).

Wandansari, \& Y. (2012). Faktor Protektif pada Penyesuaian Sosial Anak Berbakat. Jurnal Insan Media Psikologi, 13 (2). 